\title{
Does it take two to tango? Factors related to the ease of societal uptake of scientific knowledge
}

\author{
Julia Olmos-Peñuela ${ }^{\mathrm{a}}$, Paul Benneworth ${ }^{\mathrm{b}}$, Elena Castro-Martínez ${ }^{\mathrm{c}}$ \\ ${ }^{a}$ Departament of Management (Universitat de València); \\ ${ }^{b}$ CHEPS (University of Twente); \\ CINGENIO (CSIC-Universitat Politècnica de València)
}

\begin{abstract}
Science policy increasingly focuses on maximising societal benefits from science and technology investments, but often reduces those benefits to activities involving codifying and selling knowledge, thereby idealising best practice academic behaviours around entrepreneurial superstars. This paper argues that societal value depends on knowledge being used, making knowledge's eventual exploitation partly dependent upon on whether other users - societal or scientific - can use that knowledge, i.e. on how far new knowledge is cognate with users' existing knowledge. When scientists incorporate user knowledge in their research processes, what we call 'open research behaviours', their knowledge may be more usable. We develop a set of hypotheses concerning whether researchers' personal and professional characteristics are associated with open research behaviour, finding evidence suggesting that, whilst personal characteristics are not associated with open research behaviours, researchers that experience professional signals validating open research behaviours are more likely to demonstrate open research behaviour.
\end{abstract}

Keywords: research structures; hybrid scientific governance; research micro-practices; openness; scientists' characteristics. 


\section{Introduction}

There has been increasing interest in recent years in the public value of science, how investing in science contributes beyond the academic realm by creating new social, economic, cultural and democratic capacities (e.g. Adviesraad-voor-Wetenschaps 2007). Investment in universities has always been justified, at least implicitly, in terms of their social contributions (e.g. Rüegg 1992; Ernste 2007), and Vannevar Bush's (1945) The Endless Frontier articulated this relationship explicitly as a direct means of stimulating wider technological advance. More recently, a closer relationship has been claimed between university research and economic development (cf. Berman 2011), stimulating great interest among academic researchers and policy makers to measure the societal contribution of research.

An archetype has emerged of entrepreneurial academics undertaking research, then arranging its transfer into society and ultimately its exploitation. An emerging body of literature is trying to understand what motivates these heroic academics to engage with outside partners and ensure that their research is effectively used (e.g. D'Este and Perkmann 2011; Lam 2011). There is evidence that entrepreneurial performance can be correlated with improved research performance, and that star entrepreneurial scientists (in terms of spin-offs, patents and licensing) are also high performing scientists in terms of academic productivity and excellence, with strong research environments being highly stimulating for entrepreneurial activities (Van Looy et al. 2004; Gulbrandsen and Smeby 2005; O'Shea et al. 2005; Lowe and GonzalezBrambila 2007).

We contend that highly positive narratives overlook the negative consequences that engagement might have for academic independence and standing, and the risks that these negative effects might reduce the overall public value created by academic research (Slaughter and Leslie 1997; Bozeman 2012). There has been a focus on those kinds of relationships which are both directly evident and easily quantifiable (Donovan 2007) ignoring the sometimes indirect and non-linear pathways by which scientific knowledge drives socio-economic development (Bozeman 2000; Salter and Martin 2001). Moreover, a focus on a narrow and limited set of formal entrepreneurship mechanisms directly associated with economic activity has framed particular kinds of disciplines as more entrepreneurial than others ( $c f$. Benneworth 2015).

This restricted view on direct transactions risks framing the public value of science in ways that contains a public value failure (cf. Bozeman 2002). ${ }^{1}$ Therefore, we seek to transcend these limitations by considering public returns to science investment as systems outcome, considering which kinds of scientist ${ }^{2}$ and scientific behaviour best contribute to maximising system returns. We contribute to a burgeoning scientific debate exploring what motivates academics to take particular decisions in their research activity thereby shaping the societal value of their findings (Bateman and Hess 2015). We critique existing approaches assuming that the system-level returns are optimised when particular technology transfer transactions are maximised ${ }^{3}$. We argue that optimum aggregate public returns from science emerge when research is most generally appropriable, rather than most easily appropriable by an end-user; societal returns are maximised when scientists optimise potential for others to be able to use and build upon their knowledge. 
We ask which kinds of scientists produce the most usable knowledge on the basis of the characteristic of 'openness', understood as academics' willingness to incorporate potential users' knowledge from partners into the research process (cf. Olmos-Peñuela et al. 2015b). We propose a conceptual model relating scientist personal and professional characteristics with making their research accessible to societal users, and we explore whether there are differences in those characteristics between those who generate knowledge that is more cognate with users and then make their research more accessible and those who do not. Using a database comprising of over 1500 researchers working for the Spanish Council for Scientific Research, we test these hypotheses and are able to identify the characteristics of those researchers making their research more usable by societal users. We then reflect on what kind of researchers are best contributing to optimising the public value of the science system, arguing the need to acknowledge that the one-size-fits-all - popular archetypes of 'superstar entrepreneurial academics' creating pharmaceutical spin-off companies' - needs revising to avoid potential public value failures.

\section{From 'knowledge suitable for terminal transfers' towards 'knowledge cognate to users'}

Contemporary research policy discourses oversimplify the question of the societal value of research by focusing on value already realised (knowledge already used) rather than potential future value. That assumption represents a specific example of a more linear model problem within science, technology and innovation studies, where complex relationships between scientists and society are simplified into linear flows to create clarity and certainty in extremely complex policy environments. We are here particularly keen to avoid making a set of common-sense assumptions that frame science practices in terms of naïve (what Balconi et al. (2010) call 'straw man') linear models.

Research valorisation as a concept can potentially carry a sense of a linear model. The idea is that funding invested in one domain, 'science', produces benefits in a downstream domain, 'society' (cf. Benneworth 2015). This simplifies a systemic relationship between these domains where knowledge is produced interactively with part of the resultant shared knowledge pool continually being taken up in society (as well as by other scientists). There is a framing of valorisation as relating to a set of one-to-one transactions between knowledge producers and knowledge users, on these 'terminal transfers' by which societal users embed scientific research in the socio-economic domain (Spaapen and van Drooge 2011). Indeed Spaapen and van Drooge (2011) specify these terminal transfers rather succinctly, as formal transactions (a patent license or spin-off company), informal interactions, (an exhibition or trade show), or indirect acquisitions (an article in the popular press).

Allocating the credit for the societal benefit to the last scientist to contribute to the knowledge overlooks the various foundation pieces of knowledge upon which that final scientist as built. The business of academic knowledge production can be understood as taking place within scientific communities (Latour and Woolgar 1979; Becher and Trowler 2001). Academic knowledge production is additive, with current research building on or challenging the existing knowledge base, often mediated through institutions such as peer-review journals which serve 
to codify and embody the academic state-of-the-art. We therefore argue that rather than to give credit to purely those scientists responsible for these terminal use transactions, it is necessary to also consider research that informs those transactions. And from a system perspective, rather than maximising these terminal transactions, it is more rational to promote research with the potential to serve as a foundation for these terminal transactions.

We do this through the definition of a characteristic of knowledge as being its potential for acquisition by a user, which requires user and producer to have common understandings, definitions, concepts and assumptions thereby allowing particular items of knowledge to be transferred between institutional and community boundaries (Gertner et al. 2011). What facilitates knowledge transfer is where it is cognate with users, that producers and users are sufficiently proximate to one another in terms of their understandings to have a meaningful exchange - particularly where that exchange is not direct, for instance mediated at a distance through texts (Boschma 2005; Fromhold-Eisebith et al. 2014).

Ensuring a good flow of antecedent knowledge that can contribute effectively to terminal knowledge transfer leads to the creation of public value. ${ }^{4}$. Hence, we argue that what makes research 'usable' is therefore the characteristic that it can easily be absorbed (and used) by others, whether scientific or societal users. But of course not all scientific knowledge will ultimately be embedded in societally-used knowledge, and we are keen to avoid an output fallacy in which we argue that producing more knowledge leads to more impact. The knowledge most likely to become incorporated into terminal knowledge transfer is the one which builds on antecedent knowledge that is itself cognate with users, and hence most easily acquired by them.

\section{Open research behaviour as an antecedent of usable knowledge}

Knowledge is most likely to flow into terminal transfers (cognateness with users' interests and needs) when produced in communities where users are somehow involved in knowledge production activities (Gibbons et al. 1994; Nowotny et al. 2001; Amin and Cohendet 2004; Isaksen and Karlsen 2010). Not all community knowledge will necessarily be produced in direct interaction with users, but under such circumstances more opportunities will exist for scientific knowledge to overlap with user interests. Our heuristic here is a domain like chemical engineering, intensely practical in its orientation, although not all academics are directly oriented towards working with users. There are common scientific problems that local and wider communities seek to address; scientific problem-solving is framed to ensure that even abstract knowledge constructed without direct user reference allows other scientists (those working directly with users) to use that knowledge and transfer it to societal users (Dance 2013).

We consequently contend that it is those scientists who create knowledge drawing on external knowledge that generate new research findings (knowledge) with greater potential usability via this property of cognateness (Elam and Bertilsson 2003) - i.e. knowledge constructed drawing on external knowledge is more cognate with these external knowledge fields. Here we define external fields as those where acquiring that knowledge is a trans-paradigmatic task requiring this property of cognateness, whether with other academic disciplines, or with 
societal users. Researchers already building upon external knowledge are therefore also creating knowledge potentially cognate to these external users. Even when it is undertaken in a very fundamental way and not immediately digestible for users, by speaking to research questions within a frame at least partly regulated by users, this research has the potential to later become used if embedded into a terminal transaction.

We therefore argue via the cognateness property that the extent to which academic researchers draw on users' knowledge in their own research activities links to the later usability of that knowledge. Not all knowledge that is cognate to users will necessarily be taken up, or indeed will be useful, and as noted above we wish to avoid an input fallacy that all knowledge that can potentially somehow be used is useful. But at the same time, we do argue that not all scientifically-excellent research is equally cognate to eventual end users, and the more cognate that knowledge is to users, the greater capacity of that knowledge to be incorporated into future new scientific knowledge that is more prone to societal uptake.

To operationalise cognateness, we elsewhere defined "academic openness" as the extent to which academic researchers draw upon external knowledge (or include external interests) in their own research activities (Olmos-Peñuela et al. 2015b). Academic knowledge is created as part of a generally expanding pool of social and scientific knowledge, and its potential for future use relates to how far external knowledge has been incorporated in it. Olmos-Peñuela et al. (2015b) use particular kinds of 'open' academic research behaviours to operationalise cognateness, behaviours where a researcher's practices incorporate external user knowledge, which we here group into five distinct classes of research processes. In each micro-practice comprising these five classes, researchers' behaviours may be more or less 'open' to incorporating that outside knowledge, this incorporation not being additional to knowledge generation but intrinsic within it:

1. Reflection: the process of consolidating and reviewing past experiences and knowledge to define areas where there are gaps in existing and promising new routes forward as the basis for (as yet undefined) future research activities.

2. Inspiration: the process of seeing a challenging issue and translating that into a question which fits into a class of problems which the researcher is interested to address in their research.

3. Planning: the practicalities of planning a process by which resources are allocated in a logical way to progress from a question via analysis to new knowledge that answers that question.

4. Execution: implementing a research strategy to bring together existing resources and a research question around a robust methodology to sort out 'messy' real world data to give deeper insights.

5. Societal dissemination: making the knowledge available to others not immediately involved in that research to allow them to absorb it and utilise it as a resource in their own processes.

We also build on the idea of a 'star scientist' (Zucker and Darby 1996), a term which emerged to describe scientists making substantial contributions to their scientific field in terms of highly cited publications, research income generation and commercial impact. We define by analogy 
'open star scientists' as researchers whose research practices maximally incorporate external knowledge into their own research activities, thereby maximising the cognateness of the newly-created knowledge with those of socio-economic users. We define the class of open star scientists (hereafter stars) as the group of researchers whose behaviours are most 'open' (see Table 1 below). Conversely, we define as 'non-open star scientists' (hereafter non-stars) as the remainder of researchers.

Table 1 Descriptions of scientist open behaviour in five classes of research processes

\begin{tabular}{|l|l|l|}
\hline Research process & \multicolumn{1}{|c|}{ Description } & \multicolumn{1}{c|}{ Open behaviour } \\
\hline Reflection & $\begin{array}{l}\text { Consolidating past experiences to } \\
\text { define future knowledge gaps and } \\
\text { identify future research domains. }\end{array}$ & $\begin{array}{l}\text { Having undertaken past research with external partners: the } \\
\text { researcher has experience in seeing problems in ways that } \\
\text { incorporate user knowledge. }\end{array}$ \\
\hline Inspiration & $\begin{array}{l}\text { Taking a practical challenge and } \\
\text { conceptualizing it as a problem } \\
\text { which their research can address. }\end{array}$ & $\begin{array}{l}\text { Being inspired by use conditions (what Stokes calls 'Edison' or } \\
\text { 'Pasteur'-type researchers): they may follow research questions } \\
\text { influenced by socio-economic considerations, choosing more } \\
\text { research questions leading to more usable knowledge. }\end{array}$ \\
\hline Planning & $\begin{array}{l}\text { Setting out the steps by which } \\
\text { resources are allocated to answer } \\
\text { the research question. }\end{array}$ & $\begin{array}{l}\text { Being explicit in research proposal/ plans about how external } \\
\text { parties will be involved: 'pro-social' behaviours are more likely to } \\
\text { develop research projects which create more usable knowledge } \\
\text { (D'Este et al. 2013). }\end{array}$ \\
\hline Execution & $\begin{array}{l}\text { Executing a research plan to create } \\
\text { new knowledge and insights that } \\
\text { address the initial research question. }\end{array}$ & $\begin{array}{l}\text { Involving external knowledge resources in project execution: this } \\
\text { affects the nature of the knowledge produced and thus makes it } \\
\text { more cognate with user knowledge. }\end{array}$ \\
\hline $\begin{array}{l}\text { Societal } \\
\text { dissemination }\end{array}$ & $\begin{array}{l}\text { Assisting external agents to absorb } \\
\text { the new knowledge produced in their } \\
\text { own processes. }\end{array}$ & $\begin{array}{l}\text { Dissemination activities involve interaction with users (co-creative } \\
\text { dissemination): users provide knowledge of how they use that } \\
\text { knowledge and hence their knowledge is incorporated into the } \\
\text { final outputs. }\end{array}$ \\
\hline Source:
\end{tabular}

Source: authors' own design (following Olmos-Peñuela et al. 2015b).

\section{Characteristics associated with openness}

To characterise our open stars, we consider which kinds of variable might influence researchers' open behaviour. Our overarching distinction is between personal and professional characteristics already identified in various literatures as significant academic behavioural determinants, and we propose a set of hypotheses that each of these characteristics may be associated with our open stars. Professional characteristics include the nature of the problem being studied (experimental vs hermeneutic); the type of societal agents interested in their research; the nature of the engagement (informal vs formal - via licenses, spin-offs, etc.); the field dynamism; and research multidisciplinarity. Personal characteristics are those unique to the researcher, including age, gender, relative workplace seniority, individual non-scientific motivations for conducting research and what is important to them in their career.

\subsection{Professional characteristics associated with openness}

Professional characteristics derive from how a community of scientists organises its knowledge creation activities thereby shaping the wider environment within which individual scientists operate. There are for practical reasons a set of professional characteristics which we might have chosen to explore but for which our method, using an extant database (see section 5), does not permit. It is clear that local and institutional characteristics play an important role in determining academic willingness to use open academic behaviours (Jacobson et al. 2004; 
Zomer et al. 2010; Breznitz and Feldman 2012). However, as we use a survey from a single institution in which no specific questions of local behavioural norms were asked, we therefore do not further consider two kinds of professional characteristics, namely local context and institutional context (see also section 8).

The first set of characteristics which we argue are salient relates to the disciplinary norms of researchers' fields for incorporating users within their wider scientific decision-making, such as defining research questions, publication norms and engagement activities (Trowler et al. 2012). Some fields are strongly oriented towards creating usable knowledge, such as engineering, where the definition of what constitutes a valid scientific problem is partly dependent upon users validating its relation to an imminent real world problem. There is a growing policy consensus that STEM disciplines' norms are much more accepting of user's involvement than others - social sciences and humanities (inter alia Olmos-Peñuela et al. 2014; Benneworth 2015; Olmos-Peñuela et al. 2015a). This leads us to the following hypothesis:

$\mathrm{H} 1_{\mathrm{a}}$ : Researchers involved in STEM disciplines are more open than those in SSH disciplines.

Related to this, humanities in particular have come in for extended criticism because of their hermeneutic rather than experimental modes of knowledge creation, and their tendency to create understanding of particular individual situations rather than precise answers to questions (Garland 2012; Brewer 2013; Small 2013). A technological problem is one about which objective knowledge is useful and possible, whilst in humanistic knowledge production the positionality and subjectivity of the researcher makes that transferability much more difficult: this characteristic is what Hessels and Van Lente (2008) refer to as disciplinary finality. Experimental fields transfer their knowledge to other fields at the level of natural language, whilst in hermeneutic disciplines the knowledge is so interpretative in its nature, representing a researchers' own reflective response to a phenomenon whose validity heavily depends upon that researcher. This leads us to the following hypothesis:

$H 1_{b}$ : Researchers involved in experimental disciplines are more open than those in hermeneutic disciplines.

The second set of characteristics we define relates to external linkages, connection with partners and the extent to which the knowledge exchange relationship creates a strong mutual interdependence between partners. Open behaviour may be associated with the nature of the external linkages that a researcher has with external users. Olmos-Peñuela et al. (2014) distinguished between formal activities, based on market transactions (e.g. patent licenses and consultancy) and informal activities (such as writing in newspapers, media appearances and other not formalised interactions). Formal linkages involve an economic transaction that indicates the user has acquired the rights to the knowledge, a signal that the user therefore believes that its acquisition is desirable and can usefully be combined to create value. Conversely, informal relationships are more discretionary without obligation and unrelated to knowledge combination-creation processes. Formal relationships can be understood as relating to 'need to know' knowledge whilst informal relationships relate to 'nice to know knowledge' (Bate 2011). And whilst Bate (2011) may be able to anecdotally cite examples of informal engagement supporting user knowledge creation, an underlying economic 
transaction demonstrates objectively that a user has acquired the knowledge. This leads us to the following hypothesis:

$\mathrm{H} 2_{\mathrm{a}}$ : Researchers that primarily interact with users through formal engagement activities are more open than those using primarily informal engagement activities.

We also argue that working with user agents is indicative of openness. Although different kinds of users may acquire knowledge for different reasons, with firms seeking to solve problems, and governments more interested in understanding situations and trends, both those kinds of users still have to acquire and absorb that knowledge. Researchers that are receptive to outside interest from external agents are consequently more likely to develop cognateness with those users. In the case of the UK, for example, in the 2000s, the Ministry responsible for territorial development invested heavily in building a community of researchers who understood and could address their questions with a mix of funded projects, Ph.Ds, network meetings, and publications, a community who were receptive to their funders and created cognate knowledge. This is a specific example of users providing knowledge resources to their scientific partners to help them to solve their problems, and this is a characteristic that we would associate with openness. This leads us to the following hypothesis:

$\mathrm{H} 2_{\mathrm{b}}$ : Researchers that are aware of and receptive to more interests from external agents are more open than those that are less receptive and aware.

The third set of variables refers to the relative dynamism of the field in which researchers are involved, something identified by Van Rijnsoever et al. (2008) as influencing the way in which researchers choose to interact. In highly dynamic research fields (rapidly changing), such as biochemistry and molecular biology (Seglen 1997), researchers are confronted with new concepts, techniques, ideas and approaches, and therefore cannot afford to remain exclusively active in their existing disciplinary paradigmatic 'comfort zone'. The ability to deal with external knowledge becomes increasingly important to them, increasing their propensity to incorporate that external knowledge within their own research activities. This implies that those researchers in more dynamic fields would tend to be more open than researchers in fields where the business of science can proceed within the established paradigm. This leads us to the following hypothesis:

$\mathrm{H} 3_{\mathrm{a}}$ : Researchers in highly dynamic fields are more open than those in less dynamic fields.

Given that Van Rijnsoever et al. (2008) used a natural language definition of dynamism (asking researchers whether they were in a dynamic field), we refine their variable by distinguishing between two kinds of dynamism that may place pressure on researchers to seek out and incorporate different kinds of knowledge.

- Fields that are internally dynamic, where the scientific state-of-the-art is rapidly advancing and will have to acquire new disciplinary knowledge to ensure their knowledge is able to make a contribution. 
- Fields that are externally dynamic, where there are many new practical problems emerging demanding their attention and will need to follow these problems in order to remain well positioned.

This leads us to the following hypothesis pair:

$\mathrm{H}_{\mathrm{a} 1}$ : Researchers in highly internally dynamic fields are more open than those in less internally dynamic fields.

$\mathrm{H}_{\mathrm{a} 2}$ : Researchers in highly externally dynamic fields are more open than those in less externally dynamic fields.

A final characteristic which suggests that researchers may be using external knowledge, thereby increasing the usability of their knowledge, is multidisciplinarity (Venkataraman 1997; Shane 2000). Multidisciplinary scientific governance emerges to address particular problems, identified as being important, but which cannot be easily solved within a single disciplinary paradigm. Governance - allocating resources, effort, interest and reward to research therefore must be undertaken according to a commonly agreed set of understandings, with people from different fields needing to be able to mutually comprehend the logics of actors in other disciplines and paradigms. As multidisciplinary research involves building cognateness and real world application, we argue that multidisciplinarity is associated with researchers' openness, and posit the following hypothesis:

$\mathrm{H}_{\mathrm{b}}$ : Researchers involved in multidisciplinary collaboration are more open than those only collaborating within a single disciplinary area.

\subsection{Personal characteristics associated with openness}

Although scientific agents are strongly conditioned by their professional environments, evidence suggests that research processes are also affected by personal characteristics. Here we are primarily concerned with 'internal' characteristics which the academic cannot influence rather than experiences and competencies and so exclude factors such as past experience in industry or network size. A first personal characteristic is researcher gender. Van Rijnsoever and Hessels (2011) use gender as a predictor of multidisciplinarity, drawing on evidence from Rhoten and Pfirman (2007) of a higher propensity for working multidisciplinarily, as well as fitting with empirically identified female traits for team working, being better able to integrate diverse kinds of knowledge and networking activities. On that basis, one might expect female researchers to therefore be involved in knowledge creation processes that are more easily integrated with knowledge creation in other domains, making them more open, and hence leading to our first hypothesis relating to personal characteristics:

$\mathrm{H} 4_{\mathrm{a}}$ : Female researchers are more open than male researchers.

The second personal characteristic is the period of academic formation. In the last quarter century, science has begun to pursue entrepreneurial science (creating useful knowledge) in parallel with excellent science. We would therefore expect that those researchers whose main academic education was more recent would be more oriented towards the ideals of 
entrepreneurial science than those whose academic identities were formed in the age of the mass democratic university (Delanty 2002). Stephan and Levin (1993) noted that age tends to be negatively associated with research excellence and there might also be an effect that older researchers have a lower resource dependency than younger researchers in terms of external knowledge resources. This leads us to the following hypothesis:

$\mathrm{H} 4_{b}$ : Researchers who were formed in the age of entrepreneurial science are more open than those formed in the age of the ivory tower.

The final personal characteristic relates to the extent to which non-scientific considerations play a role in their academic workplace identity. Roach and Sauermann (2010) highlight that researchers interested in salary and labour protection tend to ensure that they can move into industry if necessary to support their labour conditions. Conversely, those that are interested in the pursuit of scientific knowledge will remain in the field, for which academic publication activity is necessary. We interpret this to mean that researchers for whom working conditions are more important than scientific novelty in their careers are more likely to maintain cognateness with potential users than those whose primary concerns relate to creating new knowledge through interesting research projects. This leads us to the following hypothesis:

$\mathrm{H} 4_{\mathrm{c}}$ : Researchers who are more focused on working conditions are more open than researchers who are more focused on contributing to scientific advance.

\section{Data and Methodology}

\subsection{Data collection and population}

Our empirical analysis focuses on the Spanish Council for Scientific Research (hereafter CSIC), Spain's largest public research organisation, with more than 14,000 employees organised into 126 research institutes covering eight areas of knowledge: humanities and social sciences; biology and biomedicine; food science and technology; materials science and technology; physical science and technology; chemical science and technology; agricultural sciences; and natural resources (CSIC 2012). Given that the explanation about the data collection, population and sample have been provided with greater details elsewhere (Olmos-Peñuela et al. 2014); for succinctness, here we focus on the most pertinent information for our empirical study.

Our study population is all CSIC researchers holding a doctoral degree, with the right to be principal investigators and to engage in contracts and agreements with external parties. This population includes both contracted post-doctoral researchers and civil servants $(4,240$ researchers). Our data come from the 2011 IMPACTO project which analysed the societal impact of public funded research with details collected via an online questionnaire completed by CSIC researchers (for more details see Olmos-Peñuela et al. 2014). The data collection process included email reminders and telephone follow-ups to ensure a final sample proportionally distributed by professional categories and areas of knowledge. The final sample covered 1,583 researchers ( $37 \%$ of the population). 
The questionnaire included information of a range of aspects related to researchers' profile and activities, their external linkages (in terms of type of external users interested in academic research, mechanism for collaboration, motivations, impediments and results of the collaborations) and dissemination activities. We have used IMPACTO data to measure open research behaviour within our different research processes (see section 3 and Olmos-Peñuela et al. 2015b) alongside with their professional and personal characteristics.

\subsection{Variables}

We tested the hypotheses presented in Section 4 with a number of variables that can be classified into the following 3 groups, namely: a) openness; b) professional characteristics; and c) personal characteristics.

\section{a) Openness}

To operationalise 'openness', following Olmos-Peñuela et al. (2015b), we identify indicators of open research behaviours within each research process presented in Section 3, namely; reflection, inspiration, planning, execution and societal dissemination. The operational definitions and descriptive statistics of the variables measuring 'openness' at these research processes are presented in Table 2.

Table 2. Operational definitions and descriptive statistics of 'openness' in different research processes

\begin{tabular}{|c|c|c|c|}
\hline Continuous variables & Measure & Sub-items & $\begin{array}{l}\text { Method and } \\
\text { descriptive } \\
\text { statistics }\end{array}$ \\
\hline $\begin{array}{l}\text { Openness during } \\
\text { planning processes }\end{array}$ & $\begin{array}{l}\text { Measured as an index on a Likert scale of } \\
\text { frequency ranging from } 1 \text { (never) to } 4 \text { (regularly) } \\
\text { regarding frequency with which the researcher } \\
\text { engages in each of the following activities when } \\
\text { conducting a research project. }\end{array}$ & $\begin{array}{l}\text { - To identify the potential results of } \\
\text { your research that can benefit } \\
\text { users } \\
\text { To identify the potential users who } \\
\text { can apply the results of your } \\
\text { research } \\
\text { To identify intermediaries in order } \\
\text { to transfer the results of your } \\
\text { results }\end{array}$ & $\begin{array}{l}\text { Sum of the three } \\
\text { items divided by the } \\
\text { number of applicable } \\
\text { items } \\
\text { Range: } 1-4 \\
\text { Mean: } 2.52 \\
\text { S.D: } 0.73 \\
\text { a Cronbach: } 0.78\end{array}$ \\
\hline $\begin{array}{l}\text { Openness during } \\
\text { execution processes }\end{array}$ & $\begin{array}{l}\text { Measured as an index on a Likert scale of } \\
\text { frequency ranging from } 1 \text { (not important) to } 4 \text { (very } \\
\text { important) regarding the degree of importance the } \\
\text { researcher attaches to each of the following items, } \\
\text { as reason for interacting with external entities } \\
\text { (firms, public government agencies, non-profit } \\
\text { organisations). }\end{array}$ & $\begin{array}{l}\text { - To keep abreast of about the areas } \\
\text { of interest of these non-academic } \\
\text { entities } \\
\text { - To test the feasibility and practical } \\
\text { application of your research } \\
\text { - To obtain information or materials } \\
\text { necessary for the development of } \\
\text { your current lines of research } \\
\text { - To explore new lines of research }\end{array}$ & $\begin{array}{l}\text { Sum of the four items } \\
\text { divided by the } \\
\text { number of applicable } \\
\text { items } \\
\text { Range: } 1-4 \\
\text { Mean: } 3.11 \\
\text { S.D: } 0.55 \\
\text { a Cronbach: } 0.71\end{array}$ \\
\hline Binary variables & Description & & $\begin{array}{l}\text { Descriptives } \\
\% \text { of ' } 1 \text { ' }\end{array}$ \\
\hline $\begin{array}{l}\text { Openness during } \\
\text { reflection processes }\end{array}$ & \multicolumn{2}{|c|}{$\begin{array}{l}\text { Coded ' } 1 \text { ' if the researcher has experienced changes or substantial changes in the past research } \\
\text { agenda as a result of the relationships with non-academic entities, and '0' otherwise. }\end{array}$} & $27.8 \%$ \\
\hline $\begin{array}{l}\text { Openness during } \\
\text { inspiration processes }\end{array}$ & \multicolumn{2}{|c|}{$\begin{array}{l}\text { Coded ' } 1 \text { ' if the researcher scientific activity was inspired or substantially inspired by the practical } \\
\text { use and/or application of knowledge outside the academic environment, and ' } 0 \text { ' otherwise. }\end{array}$} & $71.4 \%$ \\
\hline $\begin{array}{l}\text { Openness during societal } \\
\text { dissemination processes }\end{array}$ & \multicolumn{2}{|c|}{$\begin{array}{l}\text { Coded ' } 1 \text { ' if the researcher, as a result of collaborating with non-academic entities, reported as } \\
\text { important or very important the following three results identified as co-creative dissemination } \\
\text { activities they got: 1) obtaining patents or other intellectual property right; 2) developing } \\
\text { exhibitions and/or exhibition catalogues; generating clinical guidelines, standards, and 3) codes } \\
\text { of practices), and '0' otherwise. }\end{array}$} & as \\
\hline
\end{tabular}


Source: Olmos-Peñuela et al. (2015b), following Weingart (2009), we have used this table already when publishing on this database.

Indicators for open research behaviours can be found within different types of scientists' research behaviour ( $c f$. Table 1). Researchers in our sample enacted open behaviours in all these research processes, some or indeed none of them. We are here interested in capturing the 'open star scientists' (our stars) - i.e. the most open researchers of our sample, understood as those continuously incorporating external knowledge in their research activities (cf. Section 3). We therefore focus on those researchers systematically reporting open behaviours across the full range of research processes. Hence, we use a two-step procedure to construct a new variable ('open count') that counts the number of processes during which the researcher has demonstrated above-averagely open research behaviour:

- First, we transformed the 'openness' continuous variables (i.e. planning and execution processes) into binary variables that distinguish the highest ranked researchers in terms of open research behaviour (i.e. those ranked at the top $50 \%$ of the sample), from the lowest ranked (the lowest $50 \%$ of the sample) for each of these two variables. More details about the distributions of the binary variables corresponding to open research behaviours during the planning and execution processes are provided in Table 3.

- Second, we used the three originally binary variables (i.e. reflection, inspiration and dissemination) and, along with the two new binary variables previously built (those referred to planning and execution), we created an ordinal variable named open count - ranging from 0 to 5 - measuring the number of processes in which above-averagely open research behaviours can be identified.

The distribution of the variable labelled open count indicates that $6.6 \%$ of the sample analysed demonstrated (above-averagely) openness at all the 5 research processes, whereas $22.9 \%$ did it in at least 4 processes, and $48.2 \%$ in at least 3 processes. Since we are interested in identifying stars, we focused on the top quarter of the sample as representing those whose research behaviour is open in a substantial number of research processes ( 4 or more). There is a degree of pragmatism in our choice in defining a group of open stars representing around one quarter of the sample, but it does capture those who are above-averagely open in most of their research behaviours. Therefore, we created the binary variable labelled 'stars' that identifies the $22.9 \%$ of the researchers of the sample being open in at least 4 processes ${ }^{5}$. A summary of the descriptive statistics of all the above variables related to 'openness' is presented in Table 3. 
Table 3. Descriptive statistics for 'openness' variables

\begin{tabular}{|c|c|c|c|c|c|}
\hline Openness variables & $\begin{array}{l}\text { Type of } \\
\text { variable }\end{array}$ & Range & $\%$ Yes & $\begin{array}{c}\text { Mean } \\
\text { (SD) }\end{array}$ & $\begin{array}{c}a \\
\text { Cronbach }\end{array}$ \\
\hline During reflection processes & Binary & $0-1$ & $27.8 \%$ & & \\
\hline During inspiration processes & Binary & $0-1$ & $71.4 \%$ & & \\
\hline During planning processes & Continuous & $1-4$ & & $\begin{array}{c}2.52 \\
(0.73)\end{array}$ & 0.78 \\
\hline During execution processes & Continuous & $1-4$ & & $\begin{array}{c}3.11 \\
(0.55)\end{array}$ & 0.71 \\
\hline During dissemination processes & Binary & $0-1$ & $28.5 \%$ & & \\
\hline During planning processes (top 50\%) & Binary & $0-1$ & $48.9 \%$ & & \\
\hline During execution processes (top 50\%) & Binary & $0-1$ & $50.0 \%$ & & \\
\hline Open count & Ordinal & $0-5$ & $\begin{array}{l}\text { processes: } 10.3 \% \\
1 \text { process: } 19.1 \% \\
2 \text { processes: } 22.4 \% \\
3 \text { processes: } 25.3 \% \\
4 \text { processes: } 16.3 \% \\
5 \text { processes: } 6.6 \%\end{array}$ & & \\
\hline Stars & Binary & $0-1$ & $22.9 \%$ & & \\
\hline
\end{tabular}

\section{b) Professional characteristics}

The professional characteristics considered in our empirical analysis are related with disciplinary norms (fields), external linkages (nature and type of external agent), dynamism of the field and multidisciplinarity. These characteristics have been measured through the 10 variables presented with more detail in Table 4.

Regarding disciplinary norms, our sample consists of $7.4 \%$ of researchers belonging to the area of SSH and $92.6 \%$ conducting research within STEM fields, but in the context of our methodology, this imbalance is not problematic (Olmos-Peñuela et al. 2014). When distinguishing between hermeneutic and experimental fields, only $4.9 \%$ of the sample is categorised as hermeneutic, as opposed to the $95.1 \%$ labelled as experimental. For external linkages, $43.3 \%$ of the pathways used by researchers to establish collaboration with external parties were formal. Among the type of external agents, government agencies were most commonly reported as interested in their academic research results (41.1\%), followed by firms (32.6\%), international organisations (29.8\%) and non-profit organisations (20.8\%). Regarding field dynamism, internal dynamism was reported as most important ( $96.7 \%$ of researchers regarding contributing to knowledge advance as important or very important). Conversely, external dynamism was less relevant, with $64 \%$ of researchers reporting as important or very important contributing to the resolution of socio-economic problems. Finally, $28.8 \%$ of the sample is multidisciplinary, reporting to habitually conduct their research with researchers belonging to other scientific disciplines. 
Table 4. Descriptive statistics for the variables measuring professional characteristics

\begin{tabular}{|c|c|c|}
\hline Binary variables & Description & $\begin{array}{l}\text { Descriptives } \\
\% \text { of ' } 1 \text { ' }\end{array}$ \\
\hline $\mathrm{SSH}$ & $\begin{array}{l}\text { Binary variable coded ' } 1 \text { ' if the researcher belongs to the area of Social Science and } \\
\text { Humanities (SSH), otherwise 'O'(STEM) }\end{array}$ & $7.4 \%$ \\
\hline Hermeneutic & $\begin{array}{l}\text { Binary variable coded ' } 1 \text { ' if the researcher belongs to the area of Humanities }(\mathrm{H}) \text {, otherwise ' } 0 \text { ' } \\
\text { (Experimental: SS+STEM)'. }\end{array}$ & $4.9 \%$ \\
\hline Firm & $\begin{array}{l}\text { Binary variable coded ' } 1 \text { ' if researcher reports that firms are interested or significantly } \\
\text { interested in its research, otherwise ' } 0 \text { '. }\end{array}$ & $32.6 \%$ \\
\hline Government agencies & $\begin{array}{l}\text { Binary variable coded ' } 1 \text { ' if researcher reports that government agencies are interested or } \\
\text { significantly interested in its research, otherwise ' } 0 \text { '. }\end{array}$ & $41.1 \%$ \\
\hline $\begin{array}{l}\text { Non-profit organizations } \\
\text { (NPOs) }\end{array}$ & $\begin{array}{l}\text { Binary variable coded ' } 1 \text { ' if researcher reports that non-profit organizations are interested or } \\
\text { significantly interested in its research, otherwise ' } 0 \text { '. }\end{array}$ & $20.8 \%$ \\
\hline International organisation & $\begin{array}{l}\text { Binary variable coded ' } 1 \text { ' if researcher reports that international organisations are interested or } \\
\text { significantly interested in its research, otherwise ' } 0 \text { '. }\end{array}$ & $29.8 \%$ \\
\hline Multidisciplinarity & $\begin{array}{l}\text { Binary variable coded ' } 1 \text { ' if researcher reports usually conducting research with researchers } \\
\text { from other scientific disciplines, otherwise '0'. }\end{array}$ & $28.8 \%$ \\
\hline Continuous variable & Description & $\begin{array}{l}\text { Mean (SD) } \\
\text { Range }\end{array}$ \\
\hline Formal engagement & $\begin{array}{l}\text { The percentage of the formal pathways used by a researcher to collaborate with non-academic } \\
\text { agents to the total pathways used over the last three years (more details in Olmos-Peñuela et } \\
\text { al. 2014). }\end{array}$ & $\begin{array}{l}43.3(17.94) \\
1-100\end{array}$ \\
\hline Ordinal variable & Description and distribution of the variable & $\begin{array}{l}\text { Mean (SD) } \\
\text { Range } \\
\text { Distribution (\%) }\end{array}$ \\
\hline Internal dynamic field & $\begin{array}{ll}\text { Researcher reports that to contribute to knowledge advance in the field is: } \\
\text { - } \\
\text { - } & \text { Slightly important }(=1) \\
\text { - } & \text { Important }(=3) \\
\text { - } & \text { Very important }(=4)\end{array}$ & $\begin{array}{l}3.7(0.50) \\
(1-4) \\
0.3 \% \\
3.0 \% \\
15.4 \% \\
81.3 \%\end{array}$ \\
\hline External dynamics field & $\begin{array}{l}\text { Researcher reports that to contribute to the resolution of socio-economic problems is: } \\
\text { - } \text { Not important }(=1) \\
\text { - } \quad \text { Slightly important }(=2) \\
\text { - } \quad \text { Important }(=3) \\
\text { Very important }(=4)\end{array}$ & $\begin{array}{l}2.8(0.97) \\
1-4 \\
9.6 \% \\
26.4 \% \\
32.1 \% \\
31.9 \% \\
\end{array}$ \\
\hline
\end{tabular}

a Means, SD and range are provided for ordinal variables for practical purposes, for the comparison presented in Table 6.

\section{c) Personal characteristics}

The sample's personal characteristics are presented in Table 5. The sample is skewed towards men (62.1\%), with women representing $37.9 \%$. The average age of the overall sample is 48 years old and academic ranks are distributed as follows: post-doctoral contracted researchers (18.1\%); tenured scientists (36.4\%); scientific researchers (27.2\%); and researcher professors (18.3\%). Finally, the average respondent valued as 2.8 (in a range from 1 to 4 ) the relevance assigned to its working conditions in terms of salary and job security. 
Table 5. Descriptive statistics for personal characteristics variables

\begin{tabular}{|c|c|c|}
\hline $\begin{array}{l}\text { Binary or Categorical } \\
\text { variable }\end{array}$ & Description & $\begin{array}{c}\text { Descriptives } \\
\% \text { of ' } 1 \text { ' }\end{array}$ \\
\hline Gender & Binary variable coded ' 1 ' if the researcher is a woman, otherwise ' 0 ' (man). & $37.9 \%$ \\
\hline Seniority & $\begin{array}{l}\text { According to the four academic position researchers can hold in the CSIC, the sample is } \\
\text { distributed as follows: } \\
\begin{array}{l}\text { - } \\
\text { - }\end{array} \text { Tectoral contracted scientist } \\
\text { - Scientific researcher } \\
\text { - Researcher professor }\end{array}$ & $\begin{array}{l}18.1 \% \\
36.4 \% \\
27.2 \% \\
18.3 \%\end{array}$ \\
\hline Continuous variable & Description & $\begin{array}{l}\text { Mean (SD) } \\
\text { Range }\end{array}$ \\
\hline Age & Age of the researcher in 2011 & $\begin{array}{c}48.1(9.40) \\
28-71 \\
\end{array}$ \\
\hline Working conditions & $\begin{array}{l}\text { Measured as an index on a Likert scale ranging from } 1 \text { (not important) to } 4 \text { (very important) for } \\
\text { degree of importance researcher attaches in its work to: } \\
\text { - Salary } \\
\text { Sob security } \\
\text { index was calculated as arithmetic mean of applicable sub-items divided by number of } \\
\text { applicable sub-items (a Cronbach: } 0.62 \text { ). }\end{array}$ & $\begin{array}{c}2.8(0.75) \\
1-4\end{array}$ \\
\hline
\end{tabular}

\subsection{Analysis and test considerations}

As we previously discussed, we seek to understand whether a number of professional and personal characteristics are associated with star researchers. We therefore test the hypotheses presented in Section 4 using different statistical tests, depending on the nature of the variables.

- The t-test is used for assessing hypotheses where continuous variables (following a normal distribution) capture professional and personal researchers' characteristics - i.e. nature of the collaboration $\left(\mathrm{H} 2_{a}\right)$, age $\left(\mathrm{H} 4_{b}\right)$ and working conditions $\left(\mathrm{H} 4_{c}\right)$.

- The Mann-Whitney test $(\mathrm{U})$ is applied for hypotheses where ordinal variables are used to measure professional or personal characteristics - i.e. dynamism $\left(\mathrm{H}_{\mathrm{a} 1}\right.$ \& $\left.\mathrm{H}_{\mathrm{a} 2}\right)$.

In both t-tests and Mann-Whitney tests, the null hypothesis is that there are no differences between star and non-star researchers for the professional and personal characteristics considered, and the hypothesis is rejected if the p-value is lower than $5 \%$. Both tests allow assessing whether there are statistically significant differences between star and non-star researchers

- The Chi square test $\left(\chi^{2}\right)$ is used for assessing hypotheses where variables measuring the professional or personal characteristics are binary or categorical -i.e. disciplinary norms $\left(H 1_{a}, H 1_{b}\right)$, type of external partners interested in research $\left(H 2_{b}\right)$, multidisciplinarity $\left(H 3_{b}\right)$, gender $\left(\mathrm{H}_{\mathrm{a}}\right)$ and seniority $\left(\mathrm{H}_{\mathrm{b}}\right)$. The $\mathrm{X} 2$ tests the independence or not between star and non-star researchers regarding the abovementioned characteristics, been the null hypothesis of independence rejected if the $p$-value is lower than $5 \%$.

The results of these tests are presented in Section 6. 


\section{Results}

The hypotheses presented in Section 4 have being empirically tested and are presented in Table 6 (for professional characteristics) and Table 7 (for personal characteristics). In summary, we find no evidence to back up the assertion that personal characteristics (in terms of gender, age, seniority, and values related to working conditions) differ between star and non-star researchers.

However, our most significant findings are that there are differences in the professional characteristics of the open star researchers, although these are not necessarily those we would have anticipated. Disciplinary norms were tested comparing SSH vs. STEM $\left(H 1_{a}\right)$, and hermeneutic vs. experimental $\left(\mathrm{H}_{\mathrm{b}}\right)$. For these two hypotheses, we cannot reject the null hypotheses since we get $p$-values higher than $5 \%$ (.550 and .272, respectively), which means that we do not find significant differences between star and non-star scientists according to their disciplinary norms.

We find significant statistical differences between star and non-star researchers when analysing researchers' external linkages and its nature. Indeed, star researchers use a greater share of formal interaction pathways $\left(\mathrm{H}_{2}\right)$ for external collaboration than non-star researchers ( $p$-value=.000). When focusing on the type of external agents interested in researchers' investigation $\left(\mathrm{H} 2_{\mathrm{b}}\right)$, we found that all the external partners (except government agencies) are more interested in research conducted by star researchers than by non-star researchers. These results partially validate our initial hypotheses proposing that stars collaborate more with external agents than non-stars; except for the case of collaborations with governmental agencies - where no differences are found between star and non-star researchers.

For the hypotheses regarding the field dynamism, our empirical results do not support differences for internal dynamism $\left(\mathrm{H}_{\mathrm{a} 1}\right)(\mathrm{p}$-value $=.827)$ but they do for external dynamism $\left(\mathrm{H}_{\mathrm{a} 2}\right)(\mathrm{p}$-value $=.000)$. Thus, our hypothesis about the higher dynamism of the fields of star researchers is partially supported; we find that stars are located in fields experiencing higher pressures to contribute to socio-economic problems.

The final professional characteristic considered is researchers' multidisciplinarity. Results indicate that star researchers usually collaborate more with researchers from other disciplines compared to non-star researchers ( $p$-value $=.000)$. This empirical result sustains our initial hypothesis $\left(\mathrm{H}_{\mathrm{b}}\right)$ presented in Section 4.

Regarding personal characteristic $\left(\mathrm{H} 4_{a, b, c}\right)$, we find no evidence to reject the null hypothesis that star researchers share the same characteristics than non-star researchers. This implies that none of the hypotheses presented in Section 4 for personal characteristics is supported. These results could be interpreted in the sense that, demonstrating 'openness' throughout the different research processes does not seem to be associated with researchers' personal characteristic linked to the gender, age, seniority, or work conditions. 
Table 6. Results of statistical test about differences between star and non-star researchers regarding professional characteristics

\begin{tabular}{|c|c|c|c|c|c|c|}
\hline Hypotheses & Professional characteristics & $\begin{array}{l}\text { Values for non-stars } \\
\text { (means or distributions) }\end{array}$ & $\begin{array}{c}\text { Values for stars } \\
\text { (means or distributions) }\end{array}$ & Statistics & p-values & Results \\
\hline $\mathrm{H} 1_{\mathrm{a}}$ & Field (SSH vs STEM) & $\begin{array}{l}\text { SSH: } 7.6 \% \\
\text { STEM: } 92.4 \%\end{array}$ & $\begin{array}{l}\text { SSH: } 8.7 \% \\
\text { STEM: } 91.3 \%\end{array}$ & Chi-Square & 0.550 & No differences \\
\hline $\mathrm{H} 1_{b}$ & Hermeneutic vs Experimental & $\begin{array}{l}\text { Hermeneutic: } 4.7 \% \\
\text { Experimental: } 95.3 \%\end{array}$ & $\begin{array}{l}\text { Hermeneutic: } 6.3 \% \\
\text { Experimental: } 93.7 \%\end{array}$ & Chi-Square & 0.272 & No differences \\
\hline $\mathrm{H} \mathrm{z}_{\mathrm{a}}$ & $\%$ Formal engagement & $42.64 \%$ & $46.80 \%$ & t-test & 0.000 & Formal NON-STAR $<$ Formal STAR $* * \star$ \\
\hline$H 2 b$ & Firms & $28.1 \%$ & $62.5 \%$ & Chi-Square & 0.000 & Firms NON-STAR $<$ Firms STAR $* \star *$ \\
\hline $\mathrm{H} 2 \mathrm{~b}$ & Government agencies & $41.8 \%$ & $46.7 \%$ & Chi-Square & 0.138 & No differences \\
\hline$H 2_{b}$ & Non-profit organisations & $19.0 \%$ & $31.5 \%$ & Chi-Square & 0.000 & NPO NON-STAR $_{\text {N NPO }}^{\text {STAR }}$ * \\
\hline $\mathrm{H} 2 \mathrm{~b}$ & International organisations & $27.9 \%$ & $41.0 \%$ & Chi-Square & 0.000 & Intern NON-STAR $<$ Intern STAR *** \\
\hline $\mathrm{H}_{\mathrm{a} a 1}$ & $\begin{array}{l}\text { Internal dynamism: pressure } \\
\text { to advance knowledge }\end{array}$ & $3.77 \mathrm{a}$ & $3.78^{\mathrm{a}}$ & $\begin{array}{l}\text { Mann- } \\
\text { Whitney }\end{array}$ & 0.827 & No differences \\
\hline $\mathrm{H}_{3} \mathrm{a}_{2}$ & $\begin{array}{l}\text { External dynamism: pressure } \\
\text { to solve social problems }\end{array}$ & $2.80^{a}$ & $3.42^{\mathrm{a}}$ & $\begin{array}{l}\text { Mann- } \\
\text { Whitney }\end{array}$ & 0.000 & Ext-Dynam NON-STAR $<$ Ext-Dynam STAR ${ }^{* \star \star}$ \\
\hline $\mathrm{H} 3_{\mathrm{b}}$ & Multidisciplinarity & $26.2 \%$ & $45.7 \%$ & Chi-Square & 0.000 & MultidisC NON-STAR $<$ MultidisC STAR *** \\
\hline
\end{tabular}

a Means are provided for ordinal variables for practical purposes: they indicate direction of differences between star and non-star researchers.

$* * *$ indicates that the coefficient of the statistic is significant at $1 \%$

Table 7. Results of statistical test about differences between star and non-star researchers regarding personal characteristics

\begin{tabular}{|c|c|c|c|c|c|c|}
\hline Hypotheses & Personal characteristics & $\begin{array}{l}\text { Values for non-stars } \\
\text { (means or distributions) }\end{array}$ & $\begin{array}{c}\text { Values for stars } \\
\text { (means or distributions) }\end{array}$ & Statistics & p-values & Results \\
\hline $\mathrm{H} 4_{\mathrm{a}}$ & Gender & $\begin{array}{l}\text { Male: } 63.2 \% \\
\text { Female: } 36.8 \%\end{array}$ & $\begin{array}{l}\text { Male: } 63.0 \% \\
\text { Female: } 37.0 \%\end{array}$ & Chi-Square & 0.939 & No differences \\
\hline $\mathrm{H} 4_{b}$ & Age & 48.8 & 49.1 & t-test & 0.648 & No differences \\
\hline $\mathrm{H} 4_{\mathrm{b}}$ & Seniority & $\begin{array}{l}\text { Post-doctoral: } 14.6 \% \\
\text { Tenured scientist: } 37.4 \% \\
\text { Scientific researcher: } 29.2 \% \\
\text { Researcher professor: } 18.9 \% \\
\end{array}$ & $\begin{array}{l}\text { Post-doctoral: } 15.7 \% \\
\text { Tenured scientist: } 36.7 \% \\
\text { Scientific researcher: } 25.3 \% \\
\text { Researcher professor: } 22.3 \% \\
\end{array}$ & Chi-Square & 0.424 & No differences \\
\hline $\mathrm{H} 4_{\mathrm{c}}$ & Working conditions & 2.82 & 2.90 & t-test & 0.134 & No differences \\
\hline
\end{tabular}

$\star * \star \star$ indicates that the coefficient of the statistic is significant at $1 \%$ 


\section{Discussion}

In this paper we have been concerned with trying to understand the characteristics of those scientists who are most open to making their research usable by end users (an antecedent to those terminal knowledge transfers). We have sought to critically explore the stereotype that often seems to emerge in a grey area of the literature, between research and practice, of the 'engaged academic entrepreneur', which has become a proxy for the kinds of academics whose research has the potential to contribute to society. By framing it in terms of researchers engaging in terminal knowledge transfers, there has been a tendency to frame the 'engagement heroes' of science as being those in disciplines and sectors which creates analytic knowledge that can easily be protected and exploited in contractual transactions. This has become elided with a sense that these kinds of researchers are somehow more laudable in the context of science systems facing increasing pressures to ensure that those scientific investments deliver clear societal benefits.

We see here that there is a clear risk of public value favour in mistaking those engaged in particular transactions with those responsible for creating the knowledge capacities that lead to greatest societal benefit. Our argument is that it is not just those scientists engaged in terminal knowledge transfers that are creating societally valuable knowledge; rather we must also consider those who undertake excellent research that is cognate with users whose research will contribute to terminal knowledge transfers. This provides us with a means to critically interrogate the stereotypical 'engagement hero', and create a more nuanced picture of who these scientists are (a summary of the results is presented in Table 8 below).

Table 8. Summary of professional characteristics differences between star and non-star researchers

\begin{tabular}{|c|c|c|}
\hline Hypotheses & Professional characteristics & Results \\
\hline $\mathrm{H} 1_{\mathrm{a}}$ & Field (SSH vs STEM) & No differences \\
\hline$H 1_{b}$ & Hermeneutic vs Experimental & No differences \\
\hline $\mathrm{H} 2 \mathrm{a}$ & $\%$ Formal engagement & Formal NON-STARS $<$ Formal STARS \\
\hline$H 2 b$ & Firms & FirmS NON-STARS $<$ FirmS STARS \\
\hline $\mathrm{H} 2 \mathrm{~b}$ & Government agencies & No differences \\
\hline$H 2_{b}$ & Non-profit organisations & NPO NON-STARS $<$ NPO STARS \\
\hline $\mathrm{H} 2 \mathrm{~b}$ & International organisations & Intern NON-STARS $<$ Inter STARS \\
\hline$H 3_{a 1}$ & Internal dynamism: pressure to advance knowledge & No differences \\
\hline $\mathrm{H} 3_{\mathrm{a} 2}$ & External dynamism: pressure to solve social problems & Ext-dynam NON-STARS $<$ Ext-dynam STARS \\
\hline $\mathrm{H} 3 \mathrm{~b}$ & Multidisciplinarity & MultidisC NON-STARS $<$ MultidisC STARS \\
\hline
\end{tabular}

Our results do at least partly confirm our initial stylisation of those researchers creating the most usable research. One characteristic of more open researchers (stars) is that they have a higher share of their engagements with society partners via formal mechanisms than non-star researchers: these formal mechanisms are contractual arrangements such as spin-offs, patent licensing or consultancy. Likewise, those that regard themselves as working in fields where there is a high degree of societal pressure to create advances (such as health care or energy) 
are also those that are more open. Working with firms is also strongly associated with researchers' openness. Finally, those working in multidisciplinary environments - often associated with trying to find different perspectives to solve problems that traditional disciplinary communities cannot adequately address - are more open than those that selfidentify as mono-disciplinary.

But at the same time, we see evidence that suggests that we should get beyond the picture of the white-coated biotechnology entrepreneur-academic working $24 / 7$ as the driver of science's societal contributions. Table 8 highlights a far more diverse population of scientists making a societal contribution than this one-size-fits-all stereotype. Perhaps most interesting is that we found no evidence of disciplinary differences, with SSH researchers behaving just as openly in their practices as STEM researchers - despite a tendency amongst policy-makers to see STEM as being more useful than SSH (Olmos-Peñuela et al. 2014).

Likewise, there was no difference between the different epistemologies that researchers used, with researchers rooted in interpretative-hermeneutic epistemologies being as open to outside knowledge as those using experimental-explanatory epistemologies. Significantly, working with both non-profit and international organisations - something which is much more typically associated with the 'softer' disciplines of SSH - was also associated with openness. That is perhaps unsurprising in its own terms, but emphasises that market transactions are not the only way that usable knowledge is utilised by society to improve societal conditions.

We did not find any evidence to suggest that personal characteristics were associated with increased openness, whether gender, age, job position or working conditions. Bringing these together, we see that although there are some characteristics that define open researchers, such as more formal than informal engagements, and engagement with firms, non-profit and international organisations, there are also some areas where there is a huge diversity. The fact that disciplinary area and epistemology does not affect open research behaviours is perhaps at odds with the policy stereotype of the engaged entrepreneurial engineer, and the idea that STEM subjects are more useful for society. We likewise see that this is not the same as saying that open behaviour in different disciplinary areas may bring different kinds of tensions and challenges for those seeking to implement it (see for example Pinheiro et al. 2016, in this issue).

\section{Conclusions}

We acknowledge that this is an exploratory piece of research where we have been unable to explore either local research unit or institutional characteristics. In the absence of evidence to reject our null hypotheses, we can infer that personal characteristics do not affect the propensity to include user knowledge systematically in the research process; this in turn suggests that the open star researchers in terms of creating usable knowledge are found across the academic domain with a wide variety of gender, age, academic position and commitment towards remaining in academic employment. Likewise, we find no evidence to reject the hypothesis that disciplinarity matters, with no differences in open research behaviour patterns between researchers in STEM fields and those in SSH, and similarly, between researchers in fields facing pressure to advance knowledge, and other researchers. 
We also find no evidence that might back Gulbrandsen's (2012) argument that those who are interested in their financial situation are more likely to be highly open.

However, we have also found a number of factors that are associated with open behaviour. Perhaps unsurprisingly, those who are in fields which feel pressure to solve societal problems are leading in terms of openness. Likewise, those that have a preponderance of formal rather than informal user connections are more likely to behave openly, as these are the scientists who are receiving signals - through formal transactions - that their research is usable, thereby validating their knowledge trajectory. Moreover, those that have a significant relationship with firms, international organisations and non-profit organisations behave more openly, suggesting that creating understanding and framing knowledge requires a cognateness with users' interests and needs that are associated with openness.

What our results seem to suggest is that openness is associated with scientists receiving signals from outside the field indicating that the created knowledge is valuable. This is not just a question of user knowledge driving knowledge creation processes, but also the existence of signals from other disciplines that there is a value in what is being done. Our first contention is that more consideration needs to be given to this signalling process, to understand how this functions in practice, and the effect that this has on the academics behaviours, norms and practices of those involved in creating usable knowledge. But of course, these 'signals' are received by academics in a variety of different ways reflecting both what individual academics find important, but also through the functioning of scientific governance systems. There may be ways that these scientific governance systems can be changed to give stronger and more positive signals of their research's value outside their immediately disciplinary confines.

Related to this, if policy seeks to maximise usability as well as the number of terminal use transactions, then scientific governance systems must give sufficient amplification to these external signals of the value of use to scientists, as that is associated with scientists making their research more usable, by increasing its cognateness with others (an antecedent to its eventual uptake). This means that research utilization and valorisation policy should not merely concern itself with stimulating licensing, patents and spin-offs, but with ensuring that user value signals are integrated more thoroughly into scientific governance processes more generally. There are many ways that this can be done to give positive feedback to scientists, for example in terms of supporting mechanisms for user peer review (ex ante, in fieri and ex post), and these mechanisms need to be integrated into researchers' own value systems.

In the context of a special issue regarding getting beyond 'one-size-fits-all' narratives of science, our research provides a clear suggestion that there is no 'one-size-fits-all' concerning scientists creating the most usable knowledge that best contributes to socio-economic advance. When one considers open behaviours rather than terminal knowledge transfers, we see scientists from all research backgrounds and with different methodologies that are behaving openly, and hence creating usable knowledge. Market transactions are not the only way that usable knowledge is exploited to create benefits for society. This subtle distinction does not appear to be fully reflected by contemporary policy discourses, and we argue that more consideration need be given to the implications regarding which kinds of scientists make the most contribution to this societal knowledge pool. 


\section{Acknowledgements}

The authors acknowledge the EU-Spri Forum for the PhD Circulation grant provided to Julia Olmos Peñuela and to CHEPS as her host institution. The authors acknowledge the CSIC and other IMPACTO project researchers (INGENIO \& IESA) for their hard and very satisfactory work and the CSIC researchers whose questionnaire answers permitted developing the database. The authors would also like to thank Barend van der Meulen, the Rathenau Institute, the Netherlands, for a comment on a presentation that inspired this paper, as well as to Laurens Hessels for his correspondence on the issue of research dynamism.

\section{Notes}

1. One example of this public value failure is that, in this view, the public value is maximised by academics privatizing as much of the knowledge as possible (to maximise economic income) this may well come at the expense of the use of that knowledge for wider societal gains (Slaughter and Leslie 1997).

2. In this paper, 'researcher' and 'scientist' are used interchangeably to avoid excessive repetition, acknowledging that the literature uses these two terms.

3. i.e. the transaction by which the knowledge is privatised and passed to a user (Zahra et al. 2007), such as licensing deals or spin-out company creation. Even protagonists of valorisation indicators admit that these kinds of transactions are at best a partial proxy for public returns which clearly opens the possibility for public value failure.

4. For a more elaborated version of this argument see Benneworth and Olmos-Peñuela (2014).

5. Choosing 4 processes is at least partly an emergent choice because this corresponds with around $1 / 4$ of the sample; taking 3 processes would result in around $1 / 2$ of researchers counting as stars.

\section{References}

Adviesraad-voor-Wetenschaps (2007) 'Alfa en Gamma stralen.Valorisatiebeleid voor de Alfaen Gammawetenschappen'. Rijswijk: Adviesraad voor Wetenschaps- en Technologiebeleid.

Amin, A. and Cohendet, P. (2004) Architectures of knowledge: Firms, capabilities, and communities. Oxford: Oxford University Press.

Balconi, M., Brusoni, S. and Orsenigo, L. (2010) 'In defence of the linear model: An essay', Research Policy, 39/1: 1-13.

Bate, J. (2011) The Public Value of the Humanities. London: Bloomsbury.

Bateman, T. S. and Hess, A. M. (2015) 'Different personal propensities among scientists relate to deeper vs. broader knowledge contributions', Proceedings of the National Academy of Sciences: 1-6, http://www.pnas.org/content/early/2015/02/23/1421286112.

Becher, T. and Trowler, P. R. (2001) Academic Tribes and Territories Intellectual Enquiry and the Culture of Disciplines. Buckingham: The Society for Research into Higher Education \& Open University Press.

Benneworth, P. and Olmos-Peñuela, J. (2014) 'Resolving tensions of research utilization: The value of a usability-based approach': INGENIO (CSIC-UPV) Working Paper Series. 
Benneworth, P. (2015) 'Tracing how arts and humanities research translates, circulates and consolidates in society. How have scholars been reacting to diverse impact and public value agendas?', Arts and Humanities in Higher Education, 14/1: 45-60.

Berman, E. P. (2011) Creating the market university: How academic science became an economic engine. Princenton: Princeton University Press.

Boschma, R. (2005) 'Proximity and innovation: a critical assessment', Regional Studies, 39/1: 61-74.

Bozeman, B. (2000) 'Technology transfer and public policy: a review of research and theory', Research Policy, 29/4: 627-55.

--- (2002) 'Public-value failure: When efficient markets may not do', Public Administration Review, 62 /2: 145-61.

--- (2012) 'Public Values Concepts and Criteria: The Case for "Progressive Opportunity" as a Criterion'. Paper prepared for Creating Public Values Conference, University of Minnesota, Center for Integrative Leadership, September 20-22, 2012 <http://www.leadership.umn.edu/documents/Bozeman6.4.12wtitlepage.pdf> accessed 23 March 2015.

Brewer, J. D. (2013) The Public Value of the Social Sciences: An Interpretive Essay. London: Bloomsbury.

Bush, V. (1945) 'Science, the endless frontier: A report to the President'. <http://www.nsf.gov/od/lpa/nsf50/vbush1945.htm.> accessed 12 September 2014.

CSIC (2012) 'Memoria anual del CSIC 2011'. Madrid: Consejo Superior de Investigaciones Científicas, $<$ http://documenta.wi.csic.es/alfresco/downloadpublic/direct/workspace/SpacesStore /81d3f71c-819c-4787-9147-8c18b2d64fcb/CSIC_MEMORIA_2011_alta.pdf> accessed 17 September 2013.

D'Este, P. and Perkmann, M. (2011) 'Why do academics engage with industry? The entrepreneurial university and individual motivations', The Journal of Technology Transfer, 36 /3: 316-39.

D'Este, P., Llopis, O. and Yegros, A. (2013) 'Conducting pro-social research: Cognitive diversity, research excellence and awareness about the social impact of research': INGENIO (CSIC-UPV) Working Paper Series.

Dance, A. (2013) 'Impact: Pack a punch', Nature, 502/7471: 397-98.

Delanty, G. (2002) 'The University and Modernity: A History of the Present'. In: Robins, K. and Webster, F. (eds.) The Virtual University: : Knowledge, Markets and Management, pp. 31-48. Oxford: Oxford University Press.

Donovan, C. (2007) 'The qualitative future of research evaluation', Science and Public Policy, 34/8: 585-97.

Elam, M. and Bertilsson, M. (2003) 'Consuming, Engaging and Confronting Science The Emerging Dimensions of Scientific Citizenship', European Journal of Social Theory, 6/2: 233-51.

Ernste, H. (2007) 'The international network university of the future and its local and regional impacts'. In: Harding, A., et al. (eds.) Bright satanic mills: universities, regional development and the knowledge economy, pp. 69-94. Aldershot: Ashgate.

Fromhold-Eisebith, M., Werker, C. and Vojnic, M. (2014) 'Tracing the social dimension in innovation networks'. In: Rutten, R., et al. (eds.) The Social Dynamics of Innovation Networks, pp. 221-39. London: Routledge.

Garland, R. (2012) 'The humanities: plain and simple', Arts and humanities in Higher Education, 11/3: 300-12.

Gertner, D., Roberts, J. and Charles, D. (2011) 'University-industry collaboration: a CoPs approach to KTPs', Journal of Knowledge Management, 15/4: 625-47.

Gibbons, M., et al. (1994) The new production of knowledge: the dynamics of science and research in contemporary societies. London: Sage 
Gulbrandsen, M. (2012) "But Peter's in it for the money'-the liminality of entrepreneurial scientists'. TIK WORKING PAPERS on Innovation Studies, No. 20120323 <http://www.sv.uio.no/tik/InnoWP/Gulbrandsen\%2020120323.pdf> accessed 20 March 2015.

Gulbrandsen, M. and Smeby, J.-C. (2005) 'Industry funding and university professors' research performance', Research Policy, 34/6: 932-50.

Hessels, L. K. and Van Lente, H. (2008) 'Re-thinking new knowledge production: A literature review and a research agenda', Research Policy, 37/4: 740-60.

Isaksen, A. and Karlsen, J. (2010) 'Different modes of innovation and the challenge of connecting universities and industry: case studies of two regional industries in Norway', European Planning Studies, 18/12: 1993-2008.

Jacobson, N., Butterill, D. and Goering, P. (2004) 'Organizational factors that influence university-based researchers' engagement in knowledge transfer activities', Science Communication, 25/3: 246-59.

Lam, A. (2011) 'What motivates academic scientists to engage in research commercialization:'Gold','ribbon'or 'puzzle'?', Research Policy, 40/10: 1354-68.

Latour, B. and Woolgar, S. (1979) Laboratory life: The social construction of scientific facts. London: Sage.

Lowe, R. A. and Gonzalez-Brambila, C. (2007) 'Faculty entrepreneurs and research productivity', The Journal of Technology Transfer, 32/3: 173-94.

Nowotny, H., Scott, P. and Gibbons, M. (2001) Re-thinking science: knowledge and the public in an age of uncertainty. Argentina: SciELO.

O'Shea, R. P., et al. (2005) 'Entrepreneurial orientation, technology transfer and spinoff performance of US universities', Research Policy, 34/7: 994-1009.

Olmos-Peñuela, J., Benneworth, P. and Castro-Martínez, E. (2014) 'Are 'STEM from Mars and SSH from Venus'?: Challenging disciplinary stereotypes of research's social value', Science and Public Policy, 41/3: 384-400.

--- (2015a) 'Are sciences essential and humanities elective? Disentangling competing claims for humanities' research public value', Arts and Humanities in Higher Education, 14/1: 6178.

--- (2015b) 'What stimulates researchers to make their research usable? Towards an 'openness', Minerva (forthcoming).

Pinheiro, R., Normann, R. and Johnson H. C. G. (2016) 'External engagement and the academic heartland: The case of a regionally-embedded university', in this issue.

Rhoten, D. and Pfirman, S. (2007) 'Women in interdisciplinary science: Exploring preferences and consequences', Research Policy, 36/1: 56-75.

Roach, M. and Sauermann, H. (2010) 'A taste for science? PhD scientists' academic orientation and self-selection into research careers in industry', Research Policy, 39/3: 422-34.

Rüegg, W. (1992) 'Themes'. In: Ridder-Symoens, H.d. (ed.), A history of the University in Europe, pp. 3-34. Cambridge, UK: Cambridge University Press.

Salter, A. J. and Martin, B. R. (2001) 'The economic benefits of publicly funded basic research: a critical review', Research Policy, 30/3: 509-32.

Seglen, P. O. (1997) 'Why the impact factor of journals should not be used for evaluating research', British Medical Journal, 314/7079: 498-502.

Shane, S. (2000) 'Prior knowledge and the discovery of entrepreneurial opportunities', Organization Science, 11/4: 448-69.

Slaughter, S. and Leslie, L. L. (1997) Academic Capitalism: Politics, Policies, and the Entrepreneurial University. Baltimore: The Johns Hopkins University Press.

Small, H. (2013) The value of the humanities. Oxford: Oxford University Press.

Spaapen, J. and van Drooge, L. (2011) 'Introducing 'productive interactions' in social impact assessment', Research Evaluation, 20/3: 211-18. 
Stephan, P. E. and Levin, S. G. (1993) 'Age and the Nobel Prize revisited', Scientometrics, 28/3: 387-99.

Trowler, P., Saunders, M. and Bamber, V. (2012) Tribes and Territories in the 21st Century: Rethinking the Significance of Disciplines in Higher Education. New York: Taylor \& Francis.

Van Looy, B., et al. (2004) 'Combining entrepreneurial and scientific performance in academia: towards a compounded and reciprocal Matthew-effect?', Research Policy, 33/3: 42541.

Van Rijnsoever, F. J. and Hessels, L. K. (2011) 'Factors associated with disciplinary and interdisciplinary research collaboration', Research Policy, 40/3: 463-72.

Van Rijnsoever, F. J., Hessels, L. K. and Vandeberg, R. L. (2008) 'A resource-based view on the interactions of university researchers', Research policy, 37/8: 1255-66.

Venkataraman, S. (1997) 'The distinctive domain of entrepreneurship research: An editor's perspective', Advances in entrepreneurship, firm emergence, and growth, 3: 119-38.

Weingart, P. (2009) 'Editorial for Issue 47/3', Minerva, 47/3: 237-39.

Zahra, S. A., Van de Velde, E. and Larraneta, B. (2007) 'Knowledge conversion capability and the performance of corporate and university spin-offs', Industrial and Corporate Change, 16/4: 569-608.

Zucker, L. G. and Darby, M. R. (1996) 'Star scientists and institutional transformation: Patterns of invention and innovation in the formation of the biotechnology industry', Proceedings of the National Academy of Sciences, 93/23: 12709-16. 